\title{
Correction to: Prime ideals and generalized derivations with central values on rings
}

\author{
Mamouni Abdellah ${ }^{1} \cdot$ Oukhtite Lahcen $^{2} \cdot$ Zerra Mohammed $^{2}$ (D) \\ Published online: 24 December 2020 \\ (c) Springer-Verlag Italia S.r.l., part of Springer Nature 2020
}

\section{Correction to: Rendiconti del Circolo Matematico di Palermo Series 2 https://doi.org/10.1007/s12215-020-00578-3}

The article Prime ideals and generalized derivations with central values on rings written by Mamouni Abdellah, Oukhtite Lahcen and Zerra Mohammed was originally published electronically on the publisher's internet portal (currently Springerlink) on November 20, 2020 with open access.

With the author(s)' decision to step back from Open Choice the copyright of the article changed on (December 2020) to (C) Springer-Verlag Italia S.r.l., part of Springer Nature 2020 and the article is forthwith distributed under the terms of copyright.

The original article was corrected.

Publisher's Note Springer Nature remains neutral with regard to jurisdictional claims in published maps and institutional affiliations.

The original article can be found online at https://doi.org/10.1007/s12215-020-00578-3.

Zerra Mohammed

mohamed.zerra@gmail.com

Mamouni Abdellah

a.mamouni.fste@gmail.com

Oukhtite Lahcen

oukhtitel@hotmail.com

1 Department of Mathematics, Faculty of Sciences, University Moulay Ismaïl, Meknes, Morocco

2 Department of Mathematics, Faculty of Science and Technology of Fez, University S. M. Ben Abdellah, Box 2202, Fez, Morocco 